\title{
The Diagnostic and TREatment PROTOCOLS REgulation AND THE MINOR INJURY REGULATION: REVIEW AND COMMENTARY
}

\author{
Peter B. MichalyshYN, Q.C.
}

\section{INTRODUCTION}

This comment reviews the motor vehicle accident diagnostic/treatment' and minor injury ${ }^{2}$ regulations that came into force 1 October 2004 and apply to accidents after that date. The regulations introduce new definitions, concepts and rules that are summarized below. In each case, commentary is provided for the sake of perspective and to highlight likely areas of dispute and litigation.

In a nutshell, the two new regulations promise to result in significant change, particularly at the early stages of a motor vehicle accident (MVA) "minor" injury claim. Under the treatment protocol, Section $B$ insurers are sidelined for the initial three months post-MVA while claimants and their treatment providers enter a regime aimed at expeditious recovery from what are assumed to be acute but insignificant injuries. Section B insurers must pay for an initial assessment and series of ten to 21 treatments. At the end of the initial series, or at 90 days, ${ }^{3}$ the Section $B$ insurer can accept or reject further treatment. Whether or not an injury is deemed minor, the claimant may still have a claim for ongoing Section $B$ benefits.

With regard to the minor injury regulations, as early as the same 90 days post-MVA, third party or Section A insurers can trigger the minor injury definition by calling on a certified examiner to assess the claimant. The certified examiner's assessment is prima facie evidence on the point. However, the final word on minor injury will arrive through likely drawn-out litigation involving, amongst other things, challenges under the Canadian Charter of Rights and Freedoms.

Chatwin Cox Michalyshyn LLP. Edmonton. Alberta.

Diagnostic and Treament Protocols Regulation, Alta. Reg. 122/2004 [DTPR].

Minor Injury Regulation. Alta. Reg. 123/004 (MIIR): Uhis comment only peripherally deals wilh the Automobile Acciden Insurance Benefits Amendment Regulation. Alta. Rcg. 121/2004, and changes to Section B of the S.P.I. No. I. These Regulations fall under the insurance ACl, R.S.A. 2000, c. I.3. In limited cases sooner — see section on Injury Management Consultants (IMCs) and "alcrting faclors" at Part Il.F of this comment.

- Part I of the Constitution Act, 1982, being Schedule B to the Canada Act /982 (U.K.), 1982, c. 11 [Charter]. 


\section{DIAGNOSTIC AND TREATMENT Protocols REgULATION"}

\section{A. INTRODUCTION}

These regulations apply to Section B benefits, ${ }^{6}$ but tie in as well to the Minor Injury Regulation. ${ }^{7}$ If there is an ideological underpinning to these regulations, it is that certain strains, sprains and whiplash complaints are minor, fleeting injuries that can be dispatched within no more than 12 weeks if treated competently. Implicit is the notion that inappropriate or misguided medical treatment has previously contributed to the onset of chronic whiplash states.

It will be interesting to watch the medical profession's reaction to the protocol in that it compels a certain mindset, for example, that the patient be told that symptoms from the injury are temporary and do not reflect tissue damage, that complaints of pain have no currently detectable underlying cause, that a soft collar is not advised and that the prescription of muscle relaxants and narcotics is not authorized. In these and other ways, health care practitioners are being told by regulation how to treat patients. It remains to be seen whether all treating professionals will agree that the protocols reflect "best practices." Early indications are that medical doctors at least are not entirely on board with the protocols. If that is so, patients involved in motor vehicle accidents may be prejudiced in that failure to comply with the treatment protocols may jeopardize the patient's rights under the Minor Injury Regulation.

\section{B. INJURIES INCLUDED}

The regulation carefully defines the injuries to which it applies:

s. 1 ...

(j) "sprain" means an injury to one or more of the tendons or ligaments, or to both ;

(k) "strain" means an injury to one or more muscles;

(m) "WAD injury" means a whiplash associated disorder other than one that exhibits one or both of the following:

(i) objective, demonstrable, definable and clinically relevant ncurological signs;

(ii) a fracture to or a dislocation of the spine.

These threshold definitions of sprains, strains and WAD injuries are mirrored in the Minor Injury Regulation.

Supra note I.

- Section B no-faull benefits in the S.P.F. No. 1 Alberta Standard Automobile Policy (available in pdf online: Government of Alberta <www. Finance.gov.ab.ca/publications/insurance/standard_automobile policy.pdP as amended by the Automobile Accident Insurance Benefits Amendment Regulation, supra note 2. The so-called Amended Auto Insurance Benefits (AAIB) continue to apply to claimants (I) with non-minor injuries, (2) who exhaust benefits under the protocols or (3) who do not abide by the protocols. 
Comment: Not all MVA injuries are caught by the new protocols. The WAD injury as defined above includes what are known as WAD I and II whiplash. More serious WAD III and IV injuries are not covered by either regulation. The "WAD" terminology emerges from the Quebec Task Force on whiplash. The Quebec WAD scheme is similar but not identical to the DRE scheme set out in the Guides to the Evaluation of Permanent Impairment. ${ }^{9}$ The AMA Guides are not mentioned in either regulation.

Along with the more serious WAD III and IV whiplash injuries, arguably other injuries, if caused by an MVA, are outside either regulation. These may include chronic pain, fibromyalgia, myofascial pain, depression, post-traumatic stress disorder and temporomandibular disorders (TMD), amongst others. ${ }^{10}$

\section{Strains/SPRains}

\section{EVIDENCE-BASEd PRACTICE}

When assessing a strain/sprain injury the health care practitioner" must employ the International Classification of Diseases ${ }^{12}(/ C D)$ and "evidence-based practice" when taking a history (which must include "the client's relevant past history, including physical, psychological, emotional, cognitive and social history") together with a physical examination including a "pain assessment."

"Evidence-based practice" is defined at s. 1(b) of the Regulation as "the conscientious, explicit and judicious use of current best practice in making decisions about the care of a client, integrating individual clinical expertise with the best available external clinical evidence from systematic research."

Comment: Evidence-based practice is a relatively new clinical and largely unproven approach to medical diagnosis and treatment. According to one review, the expression was coined at the medical school at McMaster University in Ontario in the 1980s. And according to even its adherents, evidence-based practice, is described as a "hot topic," "a relatively young discipline whose positive impacts are just beginning to be validated."13

Scientific Monograph of the Quebec Task Force on Whiplash Associated Disorders: Redefining "Whiplash" and Iis Managemen (Hagerstown, Md.: J.B. Lippincolt Company, 1995), cited in DTPR, supra noie 1, s. IS. Linda Cocchiareila, Gunnar B.J. Anderson \& America Medical Association, Guides to the Evaluation of Permanemt Impairment, Sth ed. (Chicago: American Medical Association, 2001) [AMA Guides]. That TMD may be a sprain/strain within the protocols is already a matter of debate. Curiously, if it is within the protocols, there is arguably inadequate provision for TMD treatment in that dentists are not included in the definition of health care practitioner. injury management consultant or certified examiner. Defined to include medical doctors, physical therapists and chiropractors (sce DTPR, supra note 1, s. l(c)).

12 "'International Classification of Diseases' means the most recent edition of the publication titled the International Statistical Classification of Diseases and Related Health Problems, Canada, published by the Canadian Institute of Health Information, based on a publication issued from time to time titled the International Statistical Classification of Diseases and Related Health Problems, published by the World Health Organization" (ibid., s. I(g)).

" David L. Sackett and William M.C. Rosenberg "Evidence-Based Medicine: What It Is and What It Isn't"' (1996) 312 Brit. Med. J. 71 at 71. 
It has been described as "medicine [that] requires you not only to read papers but to read the right papers at the right time and then to alter your behaviour (and, what is often more difficult, the behaviour of other people) in the light of what you have found."14

Arguably, evidence-based practice may be unkind to claimants who suffer from "medically unexplained"'s conditions including chronic whiplash. Some suggest that unresolved soft tissue complaints may fit within the so-called "functional somatic syndromes." ${ }^{16}$ This latter school of thought appears more in keeping with adherents of the biopsychosocial model, ${ }^{17}$ and the scheme of the Regulation. Apparently left out are those who argue that chronic soft tissue symptoms have a physical basis. ${ }^{18}$

The regulations do not set out how the $I C D$ or "evidence-based practice" are to be employed. Alberta courts have no apparent track record interpreting either document or concept.

\section{Strain/SPRAIN SEverity}

If a strain/sprain is diagnosed, its severity will be assessed on the basis of a scheme set out in the third edition of Magee's Orthopedic Physical Assessment' and reproduced in ss. 7(2) and $11(2)$ of the DTPR.

Comment: David J. Magee is a professor with the Faculty of Rehabilitation Medicine at the University of Alberta. His book is in fact in its fourth edition, ${ }^{20}$ and includes the identical table at page 24 . It is not clear why the Regulation quotes the earlier edition of the book.

The Alberta courts have no apparent track record in interpreting Dr. Magee's formulation for severity of strain/sprain injury.

\section{Strain/Sprain TrEatment}

If a strain is diagnosed, and similarly a sprain, ${ }^{21}$ it is to be treated by:

Trisha Greenhalgh, How to Read a Paper: The Basics of Evidence Based Medicine (London: BMJ Publishing Group, 1997) at 2 [cmplasis in original].

l.e., "no demonstrable pathology."

16. This group of syndromes includes other medically unexplained phenomena such as sick building syndrome, repetitive stress injury, the side effects of silicon breast implants, Gulf War syndrome, food allergies and the like.

17. See discussion on the biophysical model, infra at Part II.G.

Robert Teasell, "Collision Injury: Cause and Effect" (Paper presented to the Trial Lawyers Association of British Columbia's Essential Soft Tissue Conference, Vancouver, British Columbia, 28-29 March 2003) [unpublished]. Materials appended, with Teasells' permission, by Derck Allchurch in "Beating the Cap: A Practical Guide to the Regulations" (Paper presented at the Iegal Education Society Alberta's seminar on Personal Injury: Insurance Reform (Bill 53). Edmonton, Alberta, 14 September 2004 and Calgary, Alberta, 21 Seplember 2004) [unpublished].

David J. Magee, Orthopedic Physical Assessment, 4 th ed. (Philadelphia: W.B. Saunders, 2002) at 24.

"See DTPR, supra note 1, s. 12. 
(a) educating the client with respect to at least the following matters:

(i) the desirability of an early retum to normal activities and to work, if applicable;

(ii) an estimate of the probable length of time that symptoms will last;

(b) managing inflammation and pain, as required,

(i) by the protected use of ice;

(ii) by elevating the injured area;

(iii) by compression;

(c) teaching the client about maintaining llexibility, balance. strength and the functions of the injured area:

(d) giving advice about self-care and the disadvantage of extended dependence on health care providers:

(c) subject to section $9(3),{ }^{22}$ providing otherwise acceplable trentment that is appropriate and within the scope of practice of the person providing it ... and that is necessary. in the opinion of the health care practitioner, for the treatment or rehabilitation of the injury:

(f) any other adjunct therapy that, in the opinion of the health carc practitioner, is necessary for the treatment or rehabilitation of the injury and that is linked to the continued clinical improvement of the client. ${ }^{23}$

Comment: As noted in the Introduction, these detailed treatment rules may or may not find favour with all health care practitioners. Most of the early resistance is from medical doctors, while physical therapists and chiropractors are more accepting of the protocols.

As to ice, elevation and compression, these are three of the four components commonly referred to in treatment literature as "RICE" - rest, ice, compression and elevation. Notably "rest" is excluded in the Regulation. It appears the notion of "rest" to treat soft tissue injuries is an anathema to the overall scheme of the protocols.

\section{NUMBER OF TREATMENTS}

Without the need for approval by the insurer, a health care practitioner may authorize an assessment and up to ten visits in total for a first or second degree strain/sprain, together with certain diagnostic tests and medications and supplies. The ten visits are for the total of "medical, physical therapy, chiropractic and adjunct therapy" visits. For a third degree strain/sprain, an assessment and no more than 21 visits in total are to be authorized. ${ }^{24}$

\section{WHIPLASII (WAD) INJURIES}

Unlike the strain/sprain categories, the diagnosis of whiplash injuries is to be guided by the Quebec Task Forces rather than the $I C D$, and again by the use of "evidence-based practice." In approaching a whiplash diagnosis, a health care practitioner must take a history similar to that set out above for strains/sprains - including "the client's relevant past history, including physical, psychological, emotional, cognitive and social history" - but also including an "inquiry into alerting factors that may influence prognosis."

Ibid., s. 8.

23. Section 9(3) reads "Under these protocols, a health care practitioner may not use a visit to treat a Ist degree strain or a 2 nd degree strain by a deliberate, brief, fast thrust to move the joints of the spine beyond the normal range but within the anatomical range of motion, which generally results in an audible click or pop" (ibid.). See s. 13(3), ibid., for the same detail on sprains.

* DPTR, supra note I, ss. 15(a)(iii-iv). 
Comment: The expression "alerting factors" is not defined in the Regulation. Alerting factors are known in New South Wales as "yellow flags" — adverse prognostic indicators that suggest other treatment may be necessary. Yellow flags may be psychosocial factors (such as prior psychological disturbance, somatic tendencies), demographics factors (such as age, female, unemployed) or radiological factors (such as pre-existing physical condition), amongst other things.

In Alberta effective I October 2004, an Interpretation Bulletin has been available to health care practitioners. The Interpretation Bulletin is attributed to Dr. Larry Ohlhauser, Senior Medical Advisor to Alberta's Superintendant of Insurance. Appendix E to the Bulletin sets out what are called alerting factors for WAD I and II repeatedly shown to be associated with delayed healing: age greater than 40 ; female; more intense baseline neck or back pain; more intense baseline headache; the presence of baseline radicular symptoms; the presence of depressive or other significant emotional distress symptoms within the early weeks. ${ }^{27}$

\section{DIAGNOSIS - WAD I}

A WAD 1 injury will be diagnosed when there are:

(a) complaints of spinal pain, stiffness or tenderness;

(b) no demonstrable, definable and clinically relevant physical signs of injury;

(c) no objective, demonstrable, definable and clinically relevant neurological signs of injury;

(d) no fractures to or dislocation of the spine. ${ }^{28}$

\section{a. Treatment - WAD I}

If a WAD I injury is diagnosed, according to s. 16(2) no further investigation of the injury is warranted unless cause is shown. Under S. 17, a WAD 1 injury will be treated by:

(a) educating the client with respect to at least the following matters:

(i) the desirability of an early return to normal activities and to work, if applicable;

(ii) an estimate of the probable length of time that symptoms will last;

(iii) reassurance that there is likely no serious currently detcctable underlying cause of the pain;

(iv) the importance of postural and body mechanics control;

(v) that the use of a soft collar is not advised;

(vi) the probable factors that are responsible for other symptoms the client may be experiencing that are temporary in nature and that are not reflective of tissue damage, including
(A) disturbance of balance,
(B) disturbance or loss of hearing.
(C) limb pain or numbness,
(D) cognitive dysfunction, and
(E) jaw pain; Health Care Practitioners?: A Guide for Diagnosis, Treatment and Claims" (1 October 2004) [not 
(b) giving advice about self-care and the disadvantage of extended dependence on heath care providers;

(c) prescribing medication, including the appropriate use of analgesics, which may include short-term use of non-opoid analgesics or non-steroidal anti-inflammatory drugs, but muscle relaxants and narcotics are not authorized under these protocols for treatment of WAD I injuries;

(d) in the case of treatment of an injury,

(i) pain management, as required:

(ii) injury specific exercises;

(iii) early return to normal activities;

(iv) a home exercise program to improve range of motion:

(v) thermal therapy by the client;

(vi) preparing the client for a return to work, if appropriate;

(e) providing otherwise acceptable treatment that is appropriate and within the scope of practice of the person providing it ... and that is necessary, in the opinion of the health care practitioner, for the treatment or rehabilitation of the injury;

(f) any other adjunct therapy that, in the opinion of the health carc practitioner, is necessary for the treatment or rehabilitation of the injury and that is linked to the continued clinical improvement of the client.

\section{b. Number of Treatments}

As with strains/sprains, without insurer approval the health care practitioner may authorize an assessment and up to ten visits in total for a WAD I injury, together with certain diagnostic tests and medications and supplies. The ten visits are for the total of "medical, physical therapy, chiropractic and adjunct therapy" visits. ${ }^{29}$

\section{DIAGNOSIS - WAD II}

A WAD II injury will be diagnosed when there are:

(a) complaints of spinal pain, stiffness or 1enderness;

(b) demonstrable, definable and clinically relevant physical signs of injury, including

(i) musculoskeletal signs of decreased range of motion of the spine, and

(ii) point tenderness of spinal structures affected by the injury;

(c) no objective, demonstrable, definable and clinically relevant neurological signs of injury;

(d) no fracture to or dislocation of the spinc. ${ }^{30}$

Unlike a WAD I injury, an investigation to determine a WAD II injury and to rule out a more severe whiplash injury may include $x$-rays in the manner prescribed under $s .19(2)$ of the Regulation. However, s. 19(3) states that no MRI or CT scan will be authorized unless three plain $\mathrm{X}$-rays are equivocal.

\section{a. Treatment - WAD II}

A WAD II injury will be treated in essentially the same manner as a WAD I injury, with the exception that for WAD II s. 20(d)(v) of the Regulation specifically mentions "initiation 
of manipulation, manual therapy or mobilization, or any 2 or more of them, to improve function, if appropriate."

\section{b. Number of Treatments}

For a WAD II injury a health care practitioner may authorize an assessment under s. 21(1) and no more than 21 visits in total, together with certain diagnostic tests and medications and supplies. The 21 visits are for the total of "medical, physical therapy, chiropractic and adjunct therapy" visits. ${ }^{31}$

\section{E. STRAINS/SPRAINS/WAD INJURY TREATMENT LIMITS AND REFERRALS}

Generally, an assessment and no more than ten or 21 treatments will be authorized for multiple injuries that otherwise fall within the definitions of sprains, strains or WAD I or II injuries. $^{32}$

Section 22(2) states that the health care practitioner's authorization for anything permitted by the protocols must be in writing and issued within 90 days of the date of the accident. The authorization expires 90 days after the date of the accident unless approved by the insurer for a longer time.

\section{F. INJURY MANAGEMENT CONSULTANT (IMC)}

Within the first 90 days post-accident a health care practitioner under s. 24(1) may authorize a visit by a client to an injury management consultant if the health care practitioner:

(a) is uncertain about an injury to which the protocols apply or the diagnosis or treatment of it;

(b) believes that the injury

(i) is not resolving appropriately, or

(ii) is not resolving within the time expected and the practitioner requires another opinion or report.

A health care practitioner is an injury management consultant if he or she meets the requirements of his or her own profession, including that he or she is "an active practising member of that person's profession," ${ }^{33}$ and he or she has demonstrated to the satisfaction of the council of that person's profession that he or she is:

(i) knowledgeable with regard to the biopsychosocial model,

(ii) knowledgeable with regard to the assessment of acute and chronic pain,

(iii) is experienced in rehabilitation and disability management, and

(iv) uses evidence-based decision-making in his or her praclice. ${ }^{34}$ 
Comment: The Alberta Government's automobile insurance web site includes a list of approved medical doctors, physical therapists and chiropractor IMCs. ${ }^{35}$

\section{G. BIOPSYCHOSOCIAL MODEL}

The "biopsychosocial model" as referred to in s. 27(2)(b)(i) is not defined in the regulation.

Comment: In relation to whiplash, the biopsychosocial model proceeds on the assumption that no scientific evidence exists that WAD I/Il whiplash injuries cause serious physical damage to the soft tissues that could explain chronic pain. ${ }^{16}$ The model sees chronic whiplash as a "social disorder."

Again in the whiplash context one of most prominent advocates of the biopsychosocial model is Dr. Robert Ferrari, an Edmonton-based physician and medical examiner. Ferrari describes the model in the following terms:

The biopsychosocial model suggests that we need to change our approach to chronic pain: chronic pain is not "all in the mind", nor is it "all in the body". This model is built on the assumption that most patients are genuine, have a variely of plysical sources for pain, but that there is probably no chronic injury from the acute WAD I or 2 disorder as the source for chronic pain. The model examines the infuence of psychological reactions to the injury and the effects this has on the expectation, amplification, and attribution of the pain. ${ }^{38}$

Elsewhere, and in more colourful terms, Ferrari expresses his view of the role of compensation and greed in the biopsychosocial model:

Collision victims make choices, but they need cultural support to enact those choices. Perhaps what makes us tend to underestimate the conscious clroices of the patients is that they are blameless in the way lawyers, therapists, the media, and others, knowingly or not, encourage an illness behaviour that is at best maladaptive, and at the worst, greed driven. It is unfortunately all too easy. within the whiplash megaindustry, for those engaged in the pursuit of tertiary gain (gain from the illness of others) to act as permissive agents for those in society willing to succumb to the their [sic] characteriologic [sic] llaws of misguided righteousness, deservedness, and greed. ${ }^{39}$

See online: Government of Alberta <www.autoinsurance.gov.ab.ca>.

As noted above, this assumption is not universally accepled: e.g. Robert W. Teasell, "The Denial of Chronic Pain" (1997) 2:2 Pain Res. \& Mgmt 89, online: Pulsus Group Inc. <www.pulsus.com/Pain/ 02_02/treas_ed.htm>; Arthur Croft, "Late Whiplash: The Controversy orOrganic vs. Biopsychosocial Models" 20:2 (14 January 2002) Dynamic Chiropracilc, online: ChiroWeb.com <www.chiroweb. com/archives/20/02/index.heml>.

Robert Ferrari, "Whiplash is a Social Disorder - How So!" (2002) 44 B.C. Med. J. 307.

Robert Ferrari, "Prevention of Chronic Pain after Whiplash" (2002) 19 Emerg. Med. 526 at 527; set also R. Ferrari \& H. Schrader, "The Late Whiplash Syndrome: A Biopsychosocial Approach" (2001) 70 J. Neurol. Neurosurg. \& Psychiatry 722.

" Robert Ferrari, "Reply to Pearce" (2001) 71 Neurol. Neurosurg. \& Psychiatry 820 at 821. 
In his own writing Dr. Ferrari suggests that use of the model would represent a "drastic shif" in the medical and social paradigms surrounding whiplash claims. ${ }^{10}$ And there is at least some debate whether psychosocial factors do predict injury outcomes. ${ }^{41}$

In sum, while some questions surround the virtue or efficacy of the biopsychosocial model, there is no doubt the Regulation mandates a knowledge of the method if not its application in the claimant's diagnosis and treatment, and in the characterization of his injury as minor or otherwise.

On a final note, the biopsychosocial model as such is a virtual unknown in Alberta case law. It has been mentioned just once, in Vespa $v$. Dynes. ${ }^{42}$ In that case it was employed by psychiatrist Dr. Ken Hashman who was called on behalf of the plaintiff. Notwithstanding other factors influencing the plaintiff's condition, the trial judge found the accident caused a chronic post-traumatic stress disorder and awarded significant general and pecuniary damages accordingly.

\section{H. "Alerting Factors"}

With regard to diagnosed WAD I or WAD II injuries - but not with regard to sprains or strains - if the client has any "alerting factor that may influence prognosis," the health care practitioner must seek to reassess the client within 21 days of the accident. If the injury is not resolving, the health care practitioner must refer the client to an injury management consultant for an assessment and report. The authorization for one such visit is in addition to the 11 or 22 visits otherwise permitted according to s. 24(2).

Comment: As noted earlier, "alerting factor" is not defined, although Dr. Ohlhauser's Interpretive Bulletin provides some guidance. ${ }^{43}$ It remains unclear how such factors "may influence" prognosis. Here, it is assumed the client sees a treatment provider within 21 days, then is seen again within the same 21 days of the accident, then is referred to a consultant. It is worth asking what happens if, by no fault of the client, the client's health care practitioner fails or refuses to comply with the protocol. As noted above, early signs are that medical doctors are disinterested in the protocols, whereas physiotherapists and chiropractors have expressed more enthusiasm for them. It has been suggested that clients may see their physicians after an accident under the auspices of Alberta Health Care, then to be referred to physical therapists or chiropractors under the auspices of the treatment protocols. If this is so, the physicians' lack of enthusiasm for the protocols may be largely
academic.

This provision, together with s. 3 of the Regulation, appears to permit the claimant and/or the health care practitioner to seek further treatment beyond the minimums set out in the Findings and Outcome During a One-Year Follow-up in 117 Patients Suffering from Common Whiplash" (1994) 33 British J. Rheumatology 442. 
treatment protocols, at any point in the process. However, the Regulation is silent regarding the procedure for such applications.

\section{INJURIES UNRESOLVED AFTER 90 DAYS}

If after 90 days post-accident a sprain, strain or WAD I/II injury has not resolved or is not satisfactorily resolving, then subject to the insurer's approval the health care practitioner may refer the client to an injury management consultant (IMC) under s. 25(1). The IMC may report on the diagnosis or treatment of the client, or recommend a further assessment or a multi-disciplinary assessment of the injury, and the persons who should be included in that assessment. $^{44}$

Comment: According to s. 25(3), the insurer must approve the involvement of an IMC at this stage, and must approve the recommended treatment plan, if any. The Regulation is silent regarding disputes that may arise if the insurer refuses payment. The Regulation is unclear whether the insurer can initiate the involvement of the IMC, or seeks its own IMC, or other medical opinion in rebuttal. Presumably either party can litigate the IMC's position within the confines of the Section B contract.

Through the involvement of the IMC or otherwise, conceivably an injury that is determined to be "minor" under the Minor Injury Regulation"s may still attract significant treatment costs for the life of the Section B claim.

Further treatment may follow for what some call "late whiplash syndrome" — cases that defy the interventionist protocol treatment during the first three months. Such treatment may include psychotherapy on the biopsychosocial basis that no merely physical insult can have resulted from a strain/sprain or WAD I/II injury, and thus psychological and/or environmental factors must be driving the chronic pain presentation. Although not set out in the Regulation, a biopsychosocial treatment protocol for late whiplash syndrome has been suggested as follows:

(a) rule out the presence of diagnosable medical disease;

(b) search for psychiatric disorder;

(c) build a collaborative alliance with the patient;

(d) focus on restoring function as the goal of treatment;

(e) provide limited reassurance; and

(f) if all else fails, prescribe "cognitive-behavioral therapy."

\section{J. Claims and Payment of Claims}

Section 32 states that within ten business days of a MVA or as soon as is practicable the client or his or her health care practitioner must provide to the insurer a completed claim

4 DTPR, supra note 1, s. 25(2).

4s Supra note 2.

* Arthur J. Barsky \& Jonathan F. Borus, “Functional Somatic Syndromes” (1999) 130 Ann. Intem. Med. 910 at 916-17. 
form, the form of which is to be prescribed by the Superintendant of Insurance. A variety of forms are now available on the Alberta Government's Web site. ${ }^{47}$

Comment: Compared to the Section B claim forms that preceded the new protocols, the initial claims form - $\mathrm{AB}-1$ - was five pages long and required significantly more information.

The AB-1 form requires a Consent to be signed by the patient permitting, amongst other things, that all relevant personal information be released to the patient's insurance company. This requirement of consent is not mentioned specifically in the DTPR.

Form AB-I refers to dentists even though nowhere in the Regulation are dentists specifically referred to, as health care practitioners or otherwise. It will be debated whether TMD - an injury commonly arising in Section B and MVA claims - is included in the definition of sprain/strain.

Within five business days of receiving a completed form, the insurer must send to the applicant a decision notice either approving or refusing the claim. The notice must give reasons for any refusal. Reasons for refusal are limited. For example, the claimant is not an insured person under the Regulation; there is no contract of insurance; the injury was not caused by the accident arising from the use or operation of an automobile. ${ }^{48}$

Section 34 then states that if the insurer fails to respond to the claim within five business days, it is deemed to have approved the claim and is liable to pay the claim unless reasons exist for a subsequent denial of the claim.

An insurer under s. 35 may subsequently deny a claim in writing for essentially the same reasons set out above (for example, claimant not an insured person).

Comment: These provisions seek to prevent the insurer from delaying a decision as to coverage, but enable the insurer to deny once further coverage details are available.

\section{MINOR INJURY REGULATION"}

\section{A. INTRODUCTION}

In a nutshell, a claimant will have sustained a minor injury and thus will be entitled to no more than $\$ 4,000$ in non-pecuniary damages when diagnosed with a strain/sprain/WAD I/II injury that does not cause serious impairment. In further detail, important definitions are set out below. 


\section{B. NON-PECUNIARY LOSS}

s. 6 The total amount recoverable as damages for non-pecuniary loss for all minor injuries sustained by a claimant shall not exceed $\$ 4,000$.

Comment: It is likely that "non-pecuniary loss" refers only to general damages for pain and suffering, leaving the claimant free to pursue heads of damage such as loss of housekeeping capacity, loss of consortium and loss of opportunity/earning capacity. However, some argument may follow that these heads of damage are in a sense "nonpecuniary" as well and may thus be limited.

Advocates of a "cap" on non-pecuniary awards point to the Supreme Court of Canada's 1978 decision in Andrews v. Grand \& Toy Alberta Lld. ${ }^{30}$ as a principled basis for limiting injury claims. Caps on awards for pain and suffering are in place in other jurisdictions, such as California, in the context of medical malpractice litigation, ${ }^{5 \mathbf{I}}$ and in Australia and in several Canadian provinces in the context of MVA litigation. ${ }^{52}$

\section{Minor InJuRY}

A minor injury is defined by s. I(h) as a strain, sprain or WAD injury caused by an accident that does not result in "a serious impairment"; WAD is further defined by s. $l(n)$ to essentially include only the WAD I/II categories from the Quebec Task Force.

Comment: WAD I/II encompass mild to moderate-severe whiplash and the vast majority of soft tissue injury claims arising from motor vehicle accidents. However, arguably WAD Il injuries result in permanently reduced range of motion at the neck or back that would attract up to 5-8 percent permanent clinical impairment as defined by the $A M A$ Guides to the Evaluation of Permanent Impairment. ${ }^{33}$ Alberta trial judges are familiar with and rely upon the AMA Guides (as noted, the standards cited in the new Regulations are foreign to the courts). Medical and other experts for both plaintiffs and defendants in injury litigation commonly make findings of clinical impairment and functional disability based on reduced motion and the $A M A$ Guides. These opinions have been accepted by Alberta trial judges and help form the basis for general damage awards typically between $\$ 30,000$ -

\$1 See e.g. Nicholas M. Pace, Laura Zakaras \& Daniela Golineli, "Capping Non-Economic Awards in Medical Malpractice Trials: California Jury Verdicts under MICRA" (Santa Monica: RAND Corp., 2004), online: Rand Institute for Civil Justice <www. rand.org/monographs/2004/RAND_MG234.pdfs, a study of the Medical Imjuny Compensation Reform Act, c. I \& 2, 1975 Cal. Stat. $\$ \$ 3949-4008$, in place in California since 1975, by which non-economic damages at trial are limited to $\$ 250,000$. The California law also limits lawyers' contingency fees.

$32 \quad$ In a recent paper, "Capping Non-Pecuniary General Danages in Traffic Injury Claims: A Comparison of the Australian and Canadian Experiences 1999-2004" (Paper presented to Negligence and Damages in an International Setting Conference, Salzburg. Austria, 23-26 September 2004) [unpublished], Shelley Milter notes that caps on general damages have been used frequently in Canada and Australia in the past five years as "instruments of social policy to help contzol inflation in the cost for the mandatory auto insurance product." Miller contends that the philosophical basis for general damages is questionable to begin with. 
$\$ 40,000$. The minor injury regulation would limit general damages in such cases to $\$ 4,000$.

\section{SERIOUS IMPAIRMENT}

"Serious impairment" is defined under s. 1(j) as meaning an impairment of a physical or cognitive function

(i) that results in a substantial inability to perform the

(A) essential tasks of the claimant's regular employment, occupation or profession, despite reasonable efforts to accommodate the claimant's impairment and the claimant's reasonable efforts to use the accommodation to allow the claimant to continue the claimant's employment, occupation or profession, (B) essential tasks of the claimant's training or education in a program or course that the claimant was enrolled in or had been accepted for enrolment in at the time of the accident, despite reasonable efforts to accommodate the claimant's impaiment and the claimant's reasonable efforts to use the accommodation to allow the claimant to continue the claimant's training or education, or

(C) normal activities of the claimant's daily living,

(ii) that has been ongoing since the accident, and

(iii) that is expected not to improve substantially.

Comment: The "serious impairment" definition will doubtless be the subject of much litigation as many questions arise, including:

(a) What does "substantial inability" mean?

(b) Who is obliged to make reasonable efforts to accommodate the impairment?

(c) What are "normal activities of daily living?"

(d) Does "ongoing since the accident" mean constant or intermittent?

(e) Is "expected not to improve substantially" the same as permanent? Note that "permanent" is not used in the regulation, nor is any time limit set out in months or years.

\section{E. DEFENDANT INCLUDES INSURER}

Section $1(\mathrm{~g})(\mathrm{i})$ defines "defendant" as a person against whom an accident claim is made or may be made, including that person's insurer.

Comment: This is a significant change to current practice in that the insurer may now engage all of the provisions in the MIR well before any action is commenced, such as by calling for a certified examiner (CE) assessment 90 days after the MVA, a right not previously open to the third party insurer until as long as three years post-accident.

\section{F. INJURY "PRIMARY FACTOR"}

In assessing serious impairment, the injury must be the "primary factor" contributing to the impairment. ${ }^{\text {st }}$ 
Comment: In this provision, the Regulation seeks expressly to overrule the causation test set out in Athey $v$. Leonati. ${ }^{\text {ss }}$ Athey provides that compensable injuries need only "materially contribute" to the claimant's post-accident condition. Litigation will follow over the meaning of "primary factor" and whether in practice it changes the Athey test.

\section{G. Protocols Not Followed/Fallure to Mitigate}

If without reasonable excuse the claimant fails to be diagnosed and treated in accordance with the Diagnostic and Treatment Protocols Regulation," then even if the injury results in serious impairment (that is, a "non-minor" injury), the claimant will be treated as if he or she sustained a "minor injury" and will be entitled to no more than $\$ 4,000$ in non-pecuniary damages according to s. 5 of the MIR. However, it is open to the claimant to attempt to prove that non-compliance with the protocols made no difference to his or her condition.

Comment: This is essentially a reverse onus based on a failure to mitigate; it forces the c!aimant to abide by the treatment protocol or to prove it would have made no difference. The question of "without reasonable excuse" will be litigated. That litigation may put the entire diagnostic and treatment protocol on trial in a test of its legitimacy.

On a more practical level, from the claimant's point of view presumably this onus is largely met once the claimant attends the health care practitioner in a timely fashion after the accident and complies with the suggested treatment. That said, neither regulation directs when the claimant must commence treatment within the first 90 days post-accident. However, other provisions require reporting within certain time frames (for example, the AB-1 form states within ten days of the accident or as soon as is practicable) and inferences as to timely treatment may be drawn accordingly.

\section{H. Multiple InJuRIEs}

If in addition to a "minor injury" the claimant sustains a "non-minor" injury, which itself fails to attract non-pecuniary damages of more than $\$ 4,000$, the total recovery for all injuries will not exceed $\$ 4,000$. On the other hand, if on the same example the claimant's non-minor injury attracts non-pecuniary damages above $\$ 4,000$, then entitlement is to those damages plus up to $\$ 4,000$ for the minor injury. ${ }^{57}$

\section{Certified EXaminer (CE)}

Section $8(7)$ (a) states that no attempt can be made to characterize the injury as "minor" or otherwise until at least 90 days post-accident.

Comment: This coincides with the 90-day treatment period set out in the protocols. During this period the Section B insurer has essentially no role other than to pay bills for treatment. It also suggests that, unless the claimant agrees, the third party insurer must wait at least 90 days before offering to pay up to $\$ 4,000$ to resolve the "minor injury" claim. 
At any point once 90 days have passed, any party can give notice of their intention to have a certified examiner (CE) assess the claimant for an opinion whether the injury is or is not "minor." The notice is to specify the name of the proposed CE. The other party can accept or reject the proposed CE. If no rejection comes within 14 days, the proposed CE is deemed accepted. If the parties cannot agree on a CE, the Superintendant will select one within five days. ${ }^{58}$

\section{J. Qualifications}

Unlike injury management consultants (IMCs), CEs must be medical doctors. They must also fulfill the following criteria set out under s. 16(2):

(a) be an active practicing member under the Medical Profession Act; 59

(b) pass an examination set by the College of Physicians \& Surgeons;

(c) be knowledgeable with regard to the biopsychosocial model;

(d) be knowledgeable with regard to the assessment of acute and chronic pain;

(e) be knowledgeable in the application of the International Classification of Diseases;;

(f) be experienced in rehabilitation and disability management;

(g) be competent in conducting independent assessments and third party opinions; and

(h) use evidence-based decision-making in his or her practice.

Only one assessment may be ordered according to s. 8(7)(b). Furthermore, s. 8(7)(c) states that the $C E$ cannot have treated the claimant, and cannot have been consulted by the insurer. In addition, the CE must make reasonable efforts to see the claimant within $\mathbf{3 0}$ days of the referral, ${ }^{61}$ and within 30 days thereafter must provide an opinion. ${ }^{62}$

Comment: There is a risk here to both the claimant and the insurer in that no "battle of experts" will be allowed under the Regulation. Further, the Regulation is silent regarding the role of the courts should either party object to the Superintendent of Insurance's proposed $C E$ (the parties are still entitled to such battles outside of the regulations, under the Alberta Rules of Court). Thus the third party insurer particularly may consider the timing of the "minor injury" assessment. If the injury is assessed as "minor" on the eve of limitation expiry, the same $\$ 4,000$ limit applies.

The Regulation is silent with regard to an early finding of a "non-minor" injury that, with the passage of time, becomes "minor" or alternatively an early "minor" injury that goes on to become "non-minor."

\section{K. Compliance}

In assessing whether the injury is minor, the CE may compel the claimant to produce any records he or she considers relevant to the inquiry, including any relevant diagnostic,

Ibid. ss. 8(1)-(6).

R.S.A. 2000, c. M-11.

See sitpra note 12.

$M I R$, supra note 2, s. 9.

Ibid., s. II. 
treatment or care information, and may receive from the claimant or the insurer any information that either party considers relevant to the assessment. ${ }^{63}$

If the CE cannot provide an injury opinion in the first instance, he may require the claimant to re-attend on a specific date but not later than six months after the first assessment. $^{64}$

Regarding the CE process, the claimant's injury will be deemed to be "minor" if without reasonable excuse

(a) the claimant fails to attend the examination or refuses to answer any relevant questions of the $C E$ about his medical condition or medical history, or matters referred to in the definition of "serious impairment",;s or

(b) "in any other way obstructs the certified examiner's assessment."

Comment: This is a sweeping provision that will likely result in litigation over relevance depending on the scope of the CE's inquiry. Once again, if the biopsychosocial model is employed, inquiries into the claimant's psychological history will be on the table. Such inquiries have been resisted in analogous circumstances in the past.

\section{Prima Facie Evidence}

s. 12 The opinion of the certified examiner is prima facie evidence that the claimant's injury is or is not a minor injury, as the case may bc.

Comment: As suggested above, while only one CE is permitted under the Regulation, presumably the prima facie opinion is rebuttable by other evidence. Like the registers of Injury Management Consultants available on the government's website, a list of approved CEs is now posted together with prescribed forms.

The fees of the Certified Examiner shall be paid by the party requesting the assessment. ${ }^{67}$

\section{Conclusion}

Effective only as of 1 October 2004, the diagnostic/treatment regulations are a work in progress. Further interpretation bulletins, and possibly changes to the protocols themselves, can be expected. ${ }^{68}$

Ibid., s. 11.

See supra, Part III.D.

MIR, supra note 2, s. 10(3).

Ibid., s. 13.

Section 39 mandates a review of the protocols at least every 2 years, and whenever asked to do so in writing by the respective colleges of physicians, physical therapists or chiropractors. 
While the treatment protocols have attracted the most early attention, the new minor injury rules may eclipse the protocols not long after I January 2005. From that date forward it will only be a matter of time before first medical, then judicial, determinations are made regarding when the MVA victim sustains "minor injury" for which he can collect no more than $\$ 4,000$ in general damages.

At the time of writing, a challenge to the minor injury rules under the Charter of Rights and Freedoms $s^{69}$ is in the works, although details of it are not available. In both the injury and the Charter litigation, it is expected that in principle, courts will weigh the arguably punitive effects of the minor injury rules against the justification for them - widely seen as the perceived need for motor vehicle insurance premium reform and the apparent rising costs/diminishing profits to motor vehicle insurers. To the extent these justifications have not or cannot be proven, the minor injury rules may be seen as treating accident victims unfairly, and may be interpreted accordingly. 